\title{
FIELD RESEARCH OF FIRING STORED PEAT CRITICAL CONDITIONS
}

\author{
Roman N. Kulesh ${ }^{1, *}$, and Ksenia Y. Orlova ${ }^{1}$ \\ ${ }^{1}$ National Research Tomsk Polytechnic University, 634050 Tomsk, Russia
}

\begin{abstract}
This paper presents field research: influence of different factors on peat massif firing with local outside heat source. Minimum temperatures of defined size heat source which fires the peat under the wide range of moisture value and heat-exchange conditions with terrestrial environment were found. Besides, peat massif moisture values whereby no firing is undergoing within the range of the researched temperatures of ignition source were defined.
\end{abstract}

\section{Introduction}

Today, world's peat reserves are estimated at 186 billion tons. Great reserves and their constant renewal make peat one of the most important and strategically valuable feedstock, especially taking in consideration finiteness and exhaustibility of traditional fossil fuels such as oil, natural gas and coal [1].

Peat processing technologies and its intake in different economical industries are well known and widely proven. Prevention of peat firing during drying and storage is one of the distinctive features of the peat industry [2]. Whole technology of peat consumption from digging to ultimate product could be shown as a scheme: drainage of the peat deposit, digging, storage of the produced peat, transportation, long term warehouse storage, peat consumption as a fuel. There is a list of operations involved mostly in peat digging and preparation for usage process which are characterized as special fire risk operations due to peat humidity loss. Peat is easily self-ignite and combustible material, which might be inflamed with a relatively small ignition source $[3,4]$. Often peat self-ignition is observed during its storage [5].

The main reason of stored peat firing is presence of an outside heat source. The mechanism of this process is defined firstly by appearance of separate fires (electric, mechanic or thermal sparks) at the incipient stage which fall on peat surface. In this case, if the thermal source has a sufficient energy, peat firing and deepening of the combustion source might occur. When this happens, firefighting becomes very problematical and in some cases even impossible.

Literature observation [6-15] showed that peat inflammability problem naturally and while stored is an important but understudied issue. It is possible that this might be the reason which stands on a way of practical time effective peat fire prevention and firefighting problem solution. This fact once again highlights the importance of this

\footnotetext{
*Corresponding author: ronikul@,tpu.ru
} 
research paper. Heat and mass transfer processes in inhomogeneous medium numerical modeling $[6,7]$ might be used for the purpose of the problem solvation. In order to do that one should know truth peat and peat pyrolytic decomposition products density and thermophysical properties. Unfortunately, literature observation did not allow to find mentioned above density and thermophysical properties truth value.

\section{Physical statement of the problem}

Peat is usually stored as defined size briquettes (peat stratums), for that reason the research handles the problem of peat briquette firing. Peat with density of $370 \mathrm{~kg} / \mathrm{m}^{3}$ is placed into a cylindrical cuvette with punched side surface. Cylindrical heat source with radius $r_{0}$ is placed on top of a peat stratum. The goal is to define firing parameters. The center of the heat source base is considered as an origin of coordinates. $\mathrm{X}$ and $\mathrm{Y}$ axis oriented along the top surface, and axis $\mathrm{Z}$ is vertical to the top peat surface.

The experimental variables of peat firing are firing fall time and minimum ignition source temperature, sufficient to initiate an ignition. During the experiment several thermocouples are places at different depth $\mathrm{z}$ under each heat source base. They trace temperature of certain peat stratum spots during the time of the experiment.

\section{Characterization of peat firing parameters}

It's well known, moisture has a great influence on ignition and combustion processes. Therefore, hot body ignition of peat samples with different moisture value experiments, were conducted. Research results of heat exchange processes taken place in peat layer when it had been fired with local heat source are shown on fig.1. Peat firing fall time $\left(t_{3}\right)$ with different moisture value was obtained. All experiments were held with minimum reserved energy of an ignition source which ensures peat firing. Knowing onset temperature and sizes of an ignition source it is possible to find onset heat source energy. For that reason onset and current ignition source temperature and additionally temperature of certain peat stratum spots were measured during experiments. Presented characteristic curves show onset temperature is in accord with maximum (start) temperature, curve 1. Other curves on figure 1 show change in temperature of certain peat stratum spots with determined seats.

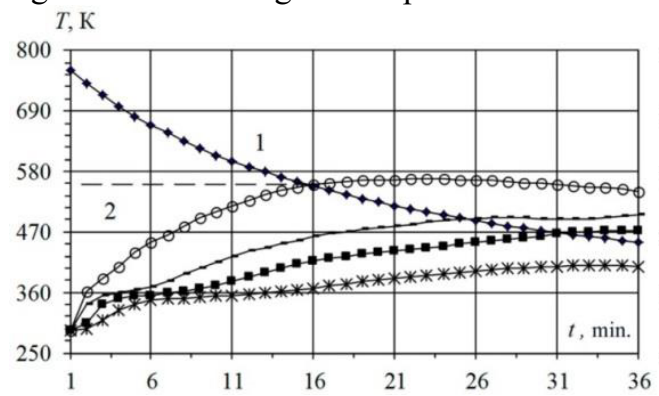

Fig. 1a. Change in temperature inside peat massif with moisture $10 \%$.

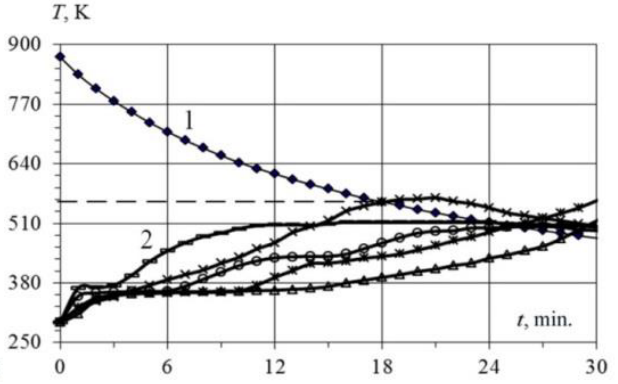

Fig. 1b. Change in temperature inside peat massif with moisture $20 \%$. 


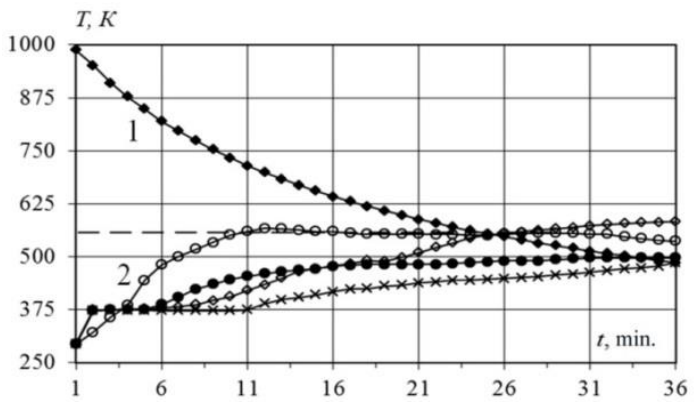

Fig. 1c. Change in temperature inside peat massif with moisture $30 \%$.

Due to the high curves density there are only several results of the experiment with typical temperature changes in relatively remote spots shown on figures above. Dashed line characterizes ignition temperature, and dashed line and curve 1 intersection point characterizes ignition time. Figure 1 functional connections show that the higher peat moisture the longer the ignition time. The moment the ignition source touches peat surface ignition temperature starts dropping monotonely (curves 1). Upon that ignition source directs its energy as to peat layer, through thermal conductivity and radiation, as to terrestrial environment (near the ground air). This process leads to rise of peat bed massif temperature which tuned in by thermocouples inside the massif. The process stays in progress till the moment when ignition source temperature at any peat field research fixed spots becomes equal. Temperature recorded at the moment is peat ignition temperature. Next stage of the experiment shows further source temperature dropping.

It is necessary to notice that peat ignition moment at any spot on the surface local temperature rise is recorded. This fact is an additional proof of peat firing presence.

Obtained temperatures lets trace the development of combustion. Figure $1 \mathrm{~b}$ shows combustion source traveling from one controlled area to another where temperature rises locally at 21 minutes in spot where combustion was absent till now. Further on combustion source moves to another controlled area. This results with temperature dropping in area of interests.

From functional connections above follows that the higher the peat moisture the longer the moisture vaporation process (vaporation takes place during first 3-9 minutes of the experiment). Moisture vaporation cools off reaction area intensively and results in its reduction in sizes due to oxygen deficit for combustion reaction from one side, and due to vaporation energy consumption. Whereas evaporated moisture filtration in peat massif pores leads to fullest peat layer exposure to heat (fig. 1c). This effect, shown by $\Delta \mathrm{T}$ curves dispersion decrease, characterizes temperatures inside peat massif (fig. $3 \mathrm{a}-\Delta \mathrm{T} \approx 200 \mathrm{~K}$, fig. $3 \mathrm{c}-\Delta \mathrm{T} \approx 100 \mathrm{~K})$.

The set of experiments with thermal insulated heat source were done to evaluate influence of ignition source and terrestrial environment heat exchange. For that reason ignition source was covered with mullite thermal isolation layer. In these conditions it's fair to assume that the ignition source transfer its energy inside peat massif only. Thermal losses through thermal isolation in this case are neglected. Experiment results with outside heat exchange conditions changes (ignition source thermal isolation) are shown on figure 2. Thermal isolation temperature was recorded in order to evaluate the ignition source thermal losses through isolation (curve 3 on figure 2).

The set of experiments is characterized by more gradual ignition source temperature decrease (as a result of thermal losses to terrestrial environment minimization) and ignition fall time decrease. This property most likely is a result of some peat volume located under the ignition source quick preheating, and as consequence, intensive gasification (pyrolysis) 
of that and neighboring peat volume. Formed pyrolysis products mixed with water vapor serve to decrease thermal energy ejection by formed convection currents from peat massif. Those currents form additional thermal isolation layer which consist of hot gasification products and water vapor. This helps to decrease ignition source and terrestrial environment heat exchange and decrease its cool down time. Given effect is also prevent oxygen diving into peat massif which also helps to decrease ignition fall time (ignition time equals to 52 minutes).

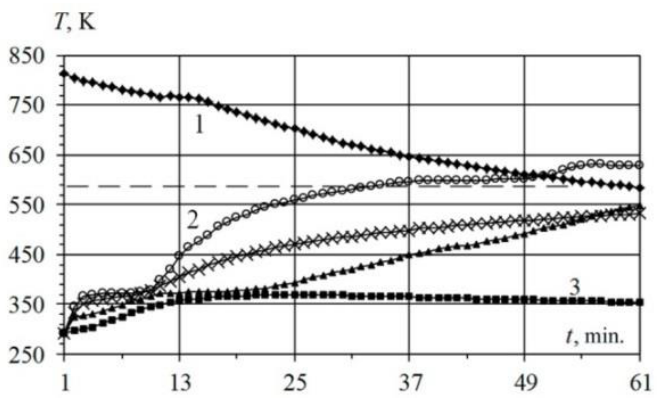

Fig. 2. Temperature change in peat massif with $20 \%$ moisture in case of thermal insulated ignition source.

All graphs show time interval which characterizes according the field research goal peat massif ignition only. Therefore the further combustion source spread is not presented. However it is important to notice that in all given experiments full peat sample burnout was detected, i.e. there were no cases of local burnout with further combustion reaction ending. The result allows concluding that local heat sources with some reserve energy might become a reason for a big fire.

It is determined that researched peat with $35-40 \%$ moisture does not light up because a burned out layer is quickly formed under the ignition source, and energy transferred through this thermal insulated layer is spent for moisture evaporation only. Water vapors create convection currents and with that force out oxygen necessary for chemical reaction and stop it from diving under the combustion source. By the time necessary mass transfer conditions for chemical transitions with terrestrial environment are set, the ignition source already does not have enough energy to initiate the combustion.

It is important that obtained results allow to make quantitative estimations taking in consideration all researched parameters and by that to be the base for further application in mathematical model and base for minimization peat ignition and its isolation recommendations development.

\section{Obtained results analysis}

Figure 3 shows generalized results of experiments with different ignition source and terrestrial environment heat exchange conditions. Base on quoted results analysis it is fair to state that $10 \%$ peat moisture increase leads to 5-7 minutes increase in ignition fall time (figure 3a). Besides, it has been elucidated that the increase in peat density will also result with an increase in ignition fall time and decrease in flame core size, i.e. as this takes place, oxygen delivery to combustion zone slows down. Conclusions of theoretical work prove the statement, stemming from experiments results [8].

The reason of experimentally found ignition fall time range spreading is most likely due to local different peat characteristics under the heat source and experimental uncertainty. In addition onset ignition source temperature is determined. What is more, besides good ignition source and working agent contact (cold state) were provided it is possible to have 
some minor inaccuracy. It happens because of orientation to decrease operation time value which might lead to only partial contact of heat source and peat surface.

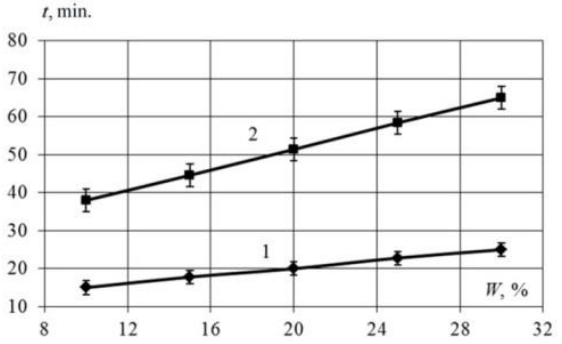

a)

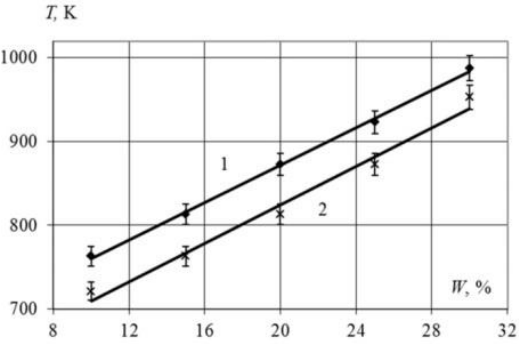

b)

Fig. 3. The ignition time and onset ignition temperature functional connection with peat moisture: 1 without insulation; 2 - with thermal insulation.

\section{Conclusion}

It has been established that $10 \%$ peat moisture decrease with constant ignition source sizes will need 100-110 K ignition source temperature increase. During experiments with a thermal insulated ignition when peat moisture increases $10 \%$ ignition source temperature decrease gap will be 80-90 K.

The obtained research revealed that there is no ignition happening if peat moisture decrease up to $35-40 \%$ even if ignition source will be heated up to furnaces' maximum temperature $-1173 \mathrm{~K}$. Hence hot ignition source of determined sizes could not become a reason for ignition of peat massif with moisture $35-40 \%$.

During set of experiments with thermal insulated ignition source the ignition fall time increases 2-2.5 times with some onset heat source temperature decrease.

Experimentally obtained data and its comparison to other authors' published results [46] prove that peat, as a feedstock with typical characteristics, is a good choice for field research. This statement allows to apply main field research results to majority of peat from other deposits.

\section{References}

1. http://www.peatsociety.org/peatlands-and-peat/global-peat-resources-country

2. A.M. Grishin, A. S. Yakimov, JEPT 81, 1 (2008)

3. A.E. Afanasyev, N.V. Churaev, Nedra (1992)

4. V.A. Nikiforof, Peat deposits development and peat mechanical processing (1979)

5. M.V. Popov, A. M. Shabarov, A. I. Gushchin, Milled peat application in power industry (1974)

6. A.N. Subbotin, Doctoral dissertation (2011)

7. X. Huang, G. Rein, H. Chen, ISC'30, 35 (2015)

8. A.N. Subbotin, R.N. Kulesh, Fire-safety (2009)

9. D.K. Thompson, B.M. Wotton, J.M. Waddington, Int. J. Wildland Fire 24 (2015)

10. A.N. Subbotin, Heat mass trans. MMF, 4 (2000)

11. A.N. Subbotin, IFJ 76 (2003)

12. A.N. Subbotin, Fire-expl. Saf. 16 (2007)

13. G. Rein, J. Garcia, A. Simeoni, V. Tihay, L. Ferrat, WIT Trans. Ec. Env. 119 (2008)

14. A. Usup, Y. Hashimoto, H. Takahashi, and H. Hayasaka, Trop. 14 (2004)

15. V. T. Kuznetsov, E. L. Loboda, Comb., Expl., Shock Waves 46 (2010) 